Байкальский государственный университет, г. Иркутск, Российская Федерация

Т. В. Файберг

Байкальский государственный университет, 2. Иркутск, Российская Федерация

\title{
УПРАВЛЕНИЕ ЛИКВИДНОСТЬЮ ЕДИНОГО СЧЕТА БЮДЖЕТА СУБЪЕКТА РОССИЙСКОЙ ФЕДЕРАЦИИ КАК МЕТОД ОБЕСПЕЧЕНИЯ БЮДЖЕТНОЙ СБАЛАНСИРОВАННОСТИ
}

\begin{abstract}
АНнотАЦИЯ. Сбалансированность бюджета является важнейшим условием его устойчивости и финансовой независимости. В настоящее время для большинства бюджетов субфедерального уровня обеспечение сбалансированности стало острой проблемой, обусловленной превышением социально-экономических обязательств над финансово-бюджетными возможностями регионов. Анализ современных научных изданий и публикаций позволил выделить ряд основных факторов, оказывающих влияние на обеспечение сбалансированности бюджетов субъектов РФ и провести их анализ. Эффективное исполнение бюджета - это один из ключевых факторов обеспечения сбалансированности, составной частью которого является управление ликвидностью бюджетного счета. В статье рассмотрен метод управления ликвидностью единого счета бюджета субъекта РФ, характеризующий способность бюджета произвести своевременную оплату денежных обязательств, и его значимость для обеспечения сбалансированности регионального бюджета. Подробно обобщены основные способы управления ликвидностью единого счета бюджета субъекта РФ, обоснованы выводы об эффективности их применения.

кЛючЕВЫЕ СЛОВА. Сбалансированность бюджета; бюджет субъекта РФ; ликвидность счета бюджета; Федеральное казначейство; управление остатками.

ИНФОРМАЦИЯ О СТАТЬЕ. Дата поступления 25 октября 2016 г.; дата принятия к печати 15 ноября 2016 г.; дата онлайн-размещения 30 ноября 2016 г.

ФИНАНСИРОВАНИЕ. Издается при финансовой поддержке государственного задания № 2014/52 на выполнение государственных работ в сфере научной деятельности в рамках базовой части проекта № 597 «Разработка методологии финансового обеспечения социально значимых расходов» (номер госрегистрации в ФГАНУ ЦИТиС 01201458899).
\end{abstract}

T. Yu. Kamasheva Baikal State University, Irkutsk, Russian Federation

T.V. Faiberg

Baikal State University, Irkutsk, Russian Federation

\section{LIQUIDITY MANAGEMENT FOR UNIFORM BUDGET ACCOUNT OF THE RUSSIAN FEDERATION ENTITY AS A METHOD OF PROVIDING BUDGET SUSTAINABILITY}

ABSTRACT. Budget sustainability is the most important condition of its stability and financial independence. At the present time, providing sustainability for the majority of sub-federal level budgets has became a pressing issue caused by exceeding the social and economic obligations over the financial and budgetary opportunities of the regions. Analysis of modern scientific publications and published papers allows to identify a number of the major factors having impact on providing sustainability of the Russian Federation entities' budgets and to carry out their analysis. Budgetary performance is one of key factors of providing sustainability, the component part of

(C) Т. Ю. Камашева, Т. В. Файберг, 2016

\section{Baikal Research Journal}

электронный научный журнал Байкальского государственного университета 
which is management of the budget account liquidity. The article considers a method of liquidity management for the uniform account of the Russian Federation entity's budget that characterizes the budget ability to make timely payments of the money liabilities and its significance in providing the regional budget sustainability. It generalizes in detail the major ways of managing the uniform account liquidity for the Russian Federation entity's budget, substantiates conclusions on their effective use. KEYWORDS. Budget sustainability; budget of the RF entity; liquidity of budget account; Federal Treasury; management of idle balances.

ARTICLE INFO. Received October 25, 2016; accepted November 15, 2016; available online November 30, 2016.

FINANCING. Governmental order No. 2014/52 on performance of state work in research activities within the base part of the project No. 597 «Devising the methodology of socially important expenses financial support» (registration No. in FGANU TsITiS 01201458899).

В соответствии с Бюджетным кодексом России любой бюджет, входящий в бюджетную систему РФ, не может быть несбалансированным ${ }^{1}$. Сбалансированность бюджета, как состояние равновесия или балансирования бюджетных расходов и источников их финансирования, представляется несущей конструкцией бюджета, обеспечивающей его устойчивость и финансовую независимость. Это достигается посредством согласованности двух противоположных сторон бюджета, выражающейся, как в количественном соответствии, так и в качественном обеспечении всех экономических пропорций и связей бюджета.

В настоящее время для большинства бюджетов субфедерального уровня обеспечение сбалансированности стало острой проблемой, обусловленной превышением социально-экономических обязательств над финансово-бюджетными возможностями региона. По данным Министерства финансов РФ, количество регионов с отрицательным бюджетным балансом принимает угрожающие размеры. По итогам 2014 г. отмечен дефицит бюджета в 77 регионах, а совокупный объем государственного долга субъектов РФ по состоянию на 1 октября 2015 г. составил 2172 , 9 млрд р. ${ }^{2}$ Состояние наращивания дефицитов региональных бюджетов и уровня государственного долга, экономические обозреватели и эксперты справедливо называют бюджетным кризисом регионов [1].

В табл. 1 представлены основные параметры исполнения регионального бюджета на примере бюджета Иркутской области в 2010-2015 гг.

Таблица 1

Основные параметры исполнения бюджета Иркутской области в 2010-2015 г2., млрд.p.

\begin{tabular}{|l|r|r|r|r|r|r|}
\hline \multirow{2}{*}{ Показатель } & \multicolumn{7}{|c|}{ Период } \\
\cline { 2 - 7 } & 2010 & 2011 & 2012 & 2013 & \multicolumn{1}{c|}{2014} & 9 мес. 2015 \\
\hline Доходы & 75,72 & 89,62 & 99,13 & 92,30 & 99,13 & 67,64 \\
\hline Расходы & 69,91 & 82,02 & 92,9 & 107,47 & 110,02 & 71,08 \\
\hline Дефицит (-) /профицит(+) & 5,81 & 7,60 & 6,23 & $-15,17$ & $-10,89$ & $-3,44$ \\
\hline Доля от собственных доходов, \% & 8,9 & 9,2 & 6,6 & 17,4 & 11,7 & 5,4 \\
\hline Государственный долг & 7,4 & 4,5 & 2,6 & 3,1 & 11,8 & 14,2 \\
\hline
\end{tabular}

Источник: Об исполнении областного бюджета за 2010 г. : закон Иркутской области от 17 окт. 2011 г. № 81-ОЗ; Об исполнении областного бюджета за 2011 г. : закон Иркутской области от 15 окт. 2012 г. № 95-О3; Об исполнении областного бюджета за 2012 г. : закон Иркутской области от 15 июля 2013 г. № 58-О3; Об исполнении областного бюджета за 2013 г. : закон Иркутской области от 10 июля 2014 г. № 92-О3; Об исполнении областного бюджета за 2014 г. : закон Иркутской области от 9 окт. 2015 г. № $72-03$.

${ }^{1}$ Бюджетный кодекс Российской Федерации : федер. закон от 31 июля 1998 г. № 145-ФЗ (ред. от 15 фев. 2016 г.). URL: http://pravo.gov.ru/isp/.

${ }^{2}$ Министерство финансов Российской Федерации : офиц. сайт. URL: http://minfin.ru.

\section{Baikal Research Journal}

электронный научный журнал Байкальского государственного университета 
Начиная с 2013 г., характерным состоянием для бюджета Иркутской области являлся бюджетный дефицит. За три последних года регион с профицитом бюджета превратился в региона-должника. Усугубление ситуации сопровождалось превышением темпов роста расходов бюджета над его доходами. Среднегодовые темпы роста доходов составили $7 \%$, а расходов - $12 \%$. Увеличение несбалансированности доходов и расходов привело к эскалации объема государственного долга бюджета Иркутской области.

Проблемы обеспечения сбалансированности региональных бюджетов принято рассматривать в контексте роста социальных обязательств по выполнению «майских» указов Президента России. Подробное исследование научных изданий и публикаций по изучаемой проблематике $[2$, с. $138-149 ; 3$, с. $270-279 ; 4-6]$ позволило выявить ряд основных факторов, которые могут оказывать влияние на обеспечение сбалансированности региональных бюджетов (рис. 1).

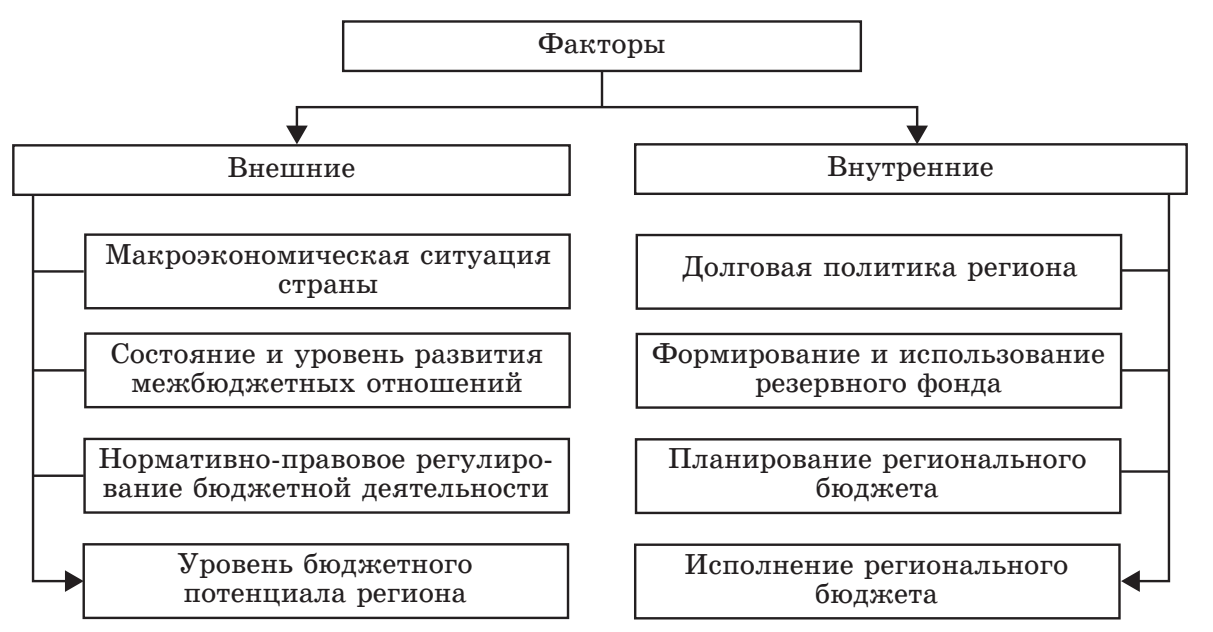

Рис. 1. Факторы, влияющие на обеспечение сбалансированности бюджетов субъектов РФ

Факторы, влияющие на сбалансированность бюджета субъекта РФ, можно условно разделить на внешние, ставящие региональный бюджет в определенные условия, которые он вынужден учитывать в бюджетной деятельности, и внутренние, зависящие от деятельности региональных органов власти и управления.

Действия внешних факторов складываются независимо от деятельности органов власти субъектов Федерации. Так, вследствие напряженной макроэкономической и геополитической ситуации последних лет, в России произошло резкое падение внутреннего регионального продукта. Текущее состояние межбюджетных отношений характеризуется недостатком собственных доходов и увеличением социальных обязательств региональных бюджетов, что приводит к росту долговых обязательств. Нормативно-правовое регулирование бюджетной деятельности устанавливается федеральным законодательством и, в этом аспекте, как отмечает В. М. Родионова, региональные бюджеты «не могут самостоятельно обеспечить сбалансированность бюджета» [7]. Кроме того, различный бюджетный потенциал субъектов РФ, определяет максимальные возможности исполнения обязательств региональных бюджетов.

Действия внутренних факторов определяются эффективностью деятельности органов государственной власти субъекта РФ. Например, долговая политика, не способная снизить долговое бремя регионов, не использование возможностей ре-

\section{Baikal Research Journal}


зервного фонда, неэкономное и нецелевое планирование расходов, несвоевременное финансовое обеспечение бюджетных обязательств, неизбежно приведет к потере сбалансированности и устойчивости бюджета.

Нивелировать влияние различного рода факторов и обеспечить состояния равновесия бюджетов субъектов РФ позволит использование эффективных методов управления сбалансированностью, нацеленных на минимизацию бюджетного дефицита, недопущение роста и снижение уровня государственного долга региона [8].

Эффективное исполнение бюджета является одним из ключевых внутренних факторов обеспечения сбалансированности регионального бюджета. Реализация полномочий по организации исполнения утвержденного бюджета ставит перед финансовыми органами субъекта РФ задачу, обеспечить в определенные сроки исполнение денежных обязательств, предъявленных к оплате получателями бюджетных средств. Успешное решение этой задачи во многом зависит от состояния единого счета регионального бюджета.

Казначейский принцип исполнения бюджета предполагает кассовое обслуживание региональных бюджетов через единые казначейские счета, открытые органам Федерального казначейства в Банке России, отдельно для каждого бюджета бюджетной системы РФ. «Единая касса» бюджетного счета предусматривает движение денежных потоков: поступление всех денежных средств и осуществление всех кассовых выплат, на одном счете бюджета. Однако, вследствие неравномерности движения денежных потоков по причине разницы в сроках и объемах кассовых поступлений и выплат, на едином счете могут образовываться как временные кассовые разрывы, так и временно свободные денежные средства.

И то, и другое, негативно сказывается на процессе обеспечения сбалансированности регионального бюджета: во-первых, привлечение дополнительных источников на покрытие кассовых разрывов влечет увеличение долговых обязательств и рост дефицита бюджета; во-вторых, излишние остатки денежных средств на счете - это нереализованная возможность получения дополнительного дохода в бюджет.

Методом обеспечения сбалансированности, направленным на достижение необходимого объема денежных средств на счете, минимизацию кассовых разрывов и эффективное использование временно свободных остатков, является управление ликвидностью единого счета бюджета.

Ликвидность единого счета бюджета - это способность соответствующего бюджета в определенный временной период произвести оплату своих обязательств [9]. Процесс управления ликвидностью единого счета бюджета предполагает:

- обеспечение достаточности объема денежных средств на едином счете регионального бюджета для гарантированной оплаты его обязательств с минимальными сопутствующими издержками;

- эффективное управление остатками денежных средств на едином счете бюджета.

Внедрение и реализация механизмов управления ликвидностью единого счета неразрывно связаны с деятельностью органов Федерального казначейства по совершенствованию системы бюджетных платежей, повышению эффективности управления финансовыми ресурсами государства с использованием единого казначейского счета. Как показал анализ экономической литературы, на федеральном уровне осуществляется активное применение способов управления ликвидностью единого счета федерального бюджета [10-12].

Несмотря на активную работу Федерального казначейства по созданию условий эффективного управления ликвидностью единого счета бюджета, теоретические и методологические исследования в этом направлении для уровня субъекта РФ практически отсутствуют.

\section{Baikal Research Journal}


Систематизация и обобщение существующих законодательных актов, позволили нам, для проведения исследования, выделить основные способы управления ликвидностью единого счета бюджета субъекта РФ.

1. Привлечение в течение финансового года временно свободных остатков средств со счета бюджетных и автономных учреждений субъекта РФ.

Министерством финансов РФ урегулирован порядок пополнения ликвидности единого счета регионального бюджета в течение финансового года за счет временно свободных остатков средств бюджетных и автономных учреждений субъекта $\mathrm{P}^{3}$. Данные денежные средства способствуют увеличению ликвидности единого счета без дополнительной платы за их использование.

Например, общая сумма остатков денежных средств бюджетных и автономных учреждений, перечисленных в бюджет Иркутской области в течение 2-х последних лет, составила более 0,5 млрд р. (рис. 2).

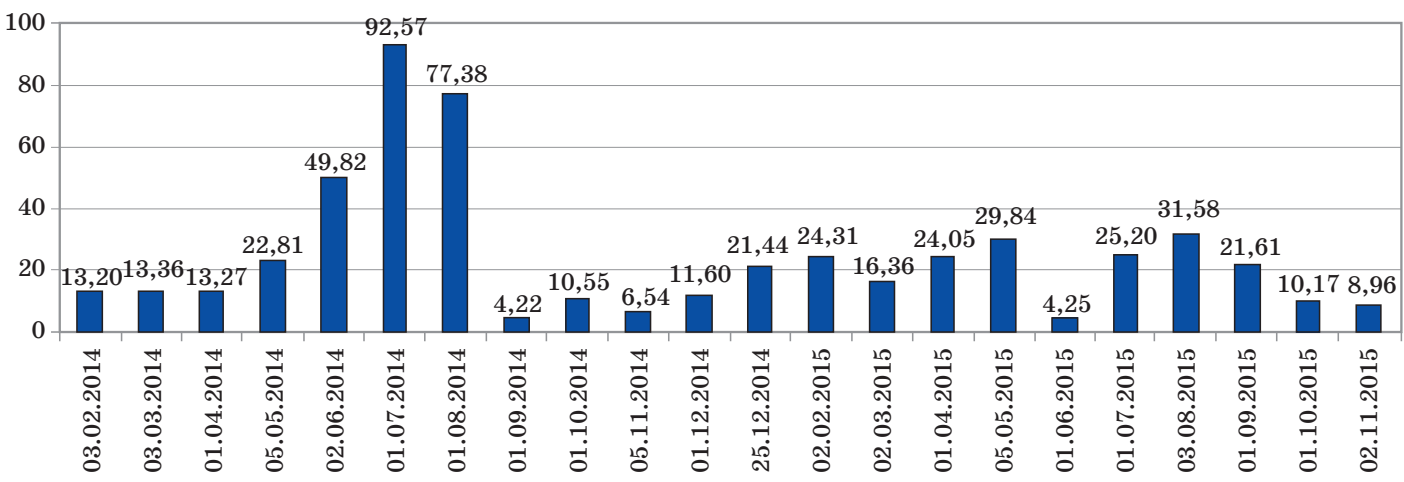

Рис. 2. Сведения об остатках средств бюджетных и автономных учреждений Иркутской области, перечисленных на счет бюджета Иркутской области, млн $p$. (составлено по данным УФК Иркутской области)

С учетом кассовых выплат бюджет Иркутской области увеличил ликвидность единого счета на общую сумму около 40 млн р. При среднегодовой процентной ставке кредитных ресурсов коммерческих организаций в размере 9,6 \% годовых, реальная экономия бюджетных средств составила около 4 млн р.

2. Бюджетные кредиты на пополнение остатков средств на счетах бюджетов субъектов Российской Федерации (местных бюджетов).

Данный тип краткосрочного бюджетного кредитования, начиная с 2014 г., применяется для покрытия кассовых разрывов региональных бюджетов, с учетом соблюдения предусмотренных законодательством требований. Процентная ставка по кредиту равна 0,1% годовых и не имеет аналогов в банковском секторе кредитования ${ }^{4}$.

Бюджет Иркутской области за два года получил бюджетных кредитов на покрытие кассовых разрывов на общую сумму 54,6 млрд р. (табл. 2).

${ }^{3} \mathrm{O}$ перечислении остатков средств бюджетных и автономных учреждений субъектов Российской Федерации (муниципальных бюджетных и автономных учреждений) с соответствующих счетов территориальных органов Федерального казначейства, открытых в учреждениях Центрального банка Российской Федерации в соответствии с законодательством Российской Федерации для отражения операций со средствами бюджетных и автономных учреждений субъектов Российской Федерации (муниципальных бюджетных и автономных учреждений), в бюджеты субъектов Российской Федерации (местные бюджеты), а также их возврата на указанные счета : приказ М-ва финансов РФ от 8 июня 2012 г. № 76н. URL: http://pravo.gov.ru/isp/.

${ }^{4}$ Об утверждении Правил предоставления бюджетных кредитов на пополнение остатков средств на счетах бюджетов субъектов Российской Федерации (местных бюджетов) : постановление Правительства РФ от 20 авг. 2013 г. № 721 (ред. от 25 июня 2014 г.). URL: http://pravo.gov.ru/isp/.

\section{Baikal Research Journal}


Таблица 2

Инфорлация об использовании бюджетных кредитов на пополнение остатков средств бюджета Иркутской области в 2014-2015 г2., млн р.

\begin{tabular}{|l|r|r|r|}
\hline \multicolumn{1}{|c|}{ Показатель } & \multicolumn{1}{c|}{2014} & \multicolumn{1}{c|}{2015} & \multicolumn{1}{c|}{ Итого } \\
\hline Бюджетные кредиты на пополнение остатков счета бюджет & 5000,00 & 49600,00 & 54600,00 \\
\hline Сумма процентов по ставке 0,1 \% годовых & 0,42 & 3,89 & 4,22 \\
\hline Сумма процентов по ставке 9,6 \% годовых & 40,00 & 396,80 & 436,80 \\
\hline
\end{tabular}

Составлено по данным УФК Иркутской области.

Приведенные данные свидетельствуют, с одной стороны, о высоком недостатке ликвидности бюджета Иркутской области, с другой, об эффективном использовании данного инструмента для обеспечения своевременности кассовых выплат.

Расходы бюджета за пользование кредитом составили 4,22 млн р. Тот же объем денежных средств, при ставке 9,6 \% годовых, стоил бы бюджету Иркутской области уже 436,80 млн р. Реальная экономия бюджетных средств составила около 432 млн р.

3. Перечисление субсидий, субвенций и иных межбюджетных трансфертов, имеющих целевое назначение под фактическую потребность.

В соответствии с федеральным законодательством, главными распорядителями средств федерального бюджета и бюджетов субъектов РФ могут быть переданы органам Федерального казначейства полномочия получателя средств по перечислению целевых средств из федерального бюджета бюджетам субъектов РФ и из бюджетов субъектов РФ муниципальным образованиям ${ }^{5}$. В этом случае, перечисление целевых средств осуществляется в пределах суммы, необходимой для оплаты денежных обязательств получателей средств, источником обеспечения которых, являются указанные целевые средства, т. е. в размере их фактической потребности на дату составления платежа.

Такой способ получил название «бюджетный аккредитив» и направлен на рациональное использование денежных средств на едином бюджетном счете. Однако, в связи с техническими недоработками, данный способ не нашел широкой практической реализации на уровне субъектов РФ

4. Размещение временно свободных остатков денежных средств регионального бюджета на банковских депозитах.

В соответствии с Бюджетным кодексом РФ, субъектам РФ предоставляется право на размещение бюджетных средств на банковских депозитах для увеличения своих доходов в процессе исполнения бюджета ${ }^{6}$.

Сутью данного способа управления ликвидностью, является определение оптимальной величины свободных остатков денежных средств на счете, выход за пределы которого, предполагает конвертацию денежных средств в банковские депозиты для получения дополнительного дохода в региональный бюджет. Однако, в связи с дефицитностью большинства региональных бюджетов, воспользоваться этим способом представляется актуальным не для всех субъектов Федерации.

По результатам исследования процесса управления ликвидностью единого счета регионального бюджета на примере бюджета Иркутской области, нами подтверждена его значимость для обеспечения сбалансированности региональных бюджетов, которая определяется:

- экономией бюджетных расходов в процессе исполнения бюджета;

${ }^{5}$ О федеральном бюджете на 2014 год и плановый период 2015 и 2016 годов : федер. закон РФ от 2 дек. 2013 г. № 349-ФЗ (ред. от 26 дек. 2014 г.). URL: http://pravo.gov.ru/isp/.

${ }^{6}$ Бюджетный кодекс Российской Федерации.

\section{Baikal Research Journal}

электронный научный журнал Байкальского государственного университета 
- сокращением уровня долговой нагрузки бюджетов и снижением кредитных рисков, связанных с замещением дорогих коммерческих кредитов не дорогими бюджетными кредитами;

- увеличением возможностей доходной базы регионального бюджета от использования финансовых ресурсов с низкой процентной ставкой;

- увеличением доходов бюджета от эффективного использования свободных остатков денежных средств на счете бюджета.

По нашему мнению, дальнейшее совершенствование данного метода обеспечения сбалансированности на региональном уровне требует практической реализации способа предоставления целевых средств местным бюджетам под фактическую потребность, что позволит поддержать уровень ликвидности бюджетного счета и сократить кассовые разрывы бюджетов субъектов РФ.

С целью обеспечения сбалансированности бюджетов субъектов РФ на долгосрочной основе, развитие данного метода обусловлено созданием эффективной системы управления ликвидностью единого счета бюджета, учитывающей экономические условия, финансовые риски, потребности и задачи конкретного субъекта РФ.

\section{Список использованной литературы}

1. Галухин А. В. Сбалансированность бюджета как условие обеспечения его устойчивости / А. В. Галухин // Вопросы территориального развития. - 2015. - № 1 (21). - C. 1-7.

2. Подъяблонская Л. М. Государственное и муниципальное управление / Л. М. Подъяблонская. - М. : Юнити-Дана, 2010. - 407 с.

3. Иркутская область в XXI веке: проблемы и ресурсы развития / А. П. Киреенко, С. В. Чупров, Л. В. Санина [и др.]. - Иркутск : Изд-во БГУЭП, 2014. - 422 с.

4. Сорокина Т. В. Совершенствование межбюджетных отношений в регионе (на примере Иркутской области) / Т. В. Сорокина // Известия Иркутской государственной экономической академии. - 2010. - № 2 (70). - С. 23-30.

5. Кузнецова Е. В. Оценка качества сбалансированности бюджетов субъектов Российской Федерации / Е. В. Кузнецова // Финансы. - 2011. - № 2. - С. 20-23.

6. Файберг Т. В. Оценка динамики социально значимых расходов Иркутской области и факторы, ее определяющие / Т. В. Файберг // Известия Иркутской государственной экономической академии. - 2014. - № 5 (97). — С. 24-27.

7. Родионова В. М. Сбалансированность бюджетов: теоретический и правовой аспекты / В. М. Родионова // Финансы. - 2012. - № 2. - С. 54-60.

8. Власенко Е. О. Исследование методов обеспечения сбалансированности бюджетной системы регионов / Е. О. Власенко // Известия Иркутской государственной экономической академии. - 2012. - № 5 (85). - С. 37-40.

9. Прокофьев С. Е. Единый казначейский счет федерального казначейства: состояние и перспективы / С. Е. Прокофьев, В. Н. Саранцев // Финансы и кредит. - 2010. № 11. - С. 4-7.

10. Пролубникова О. Е. Ликвидность единого казначейского счета, направления развития и идентификация показателей / О. Е. Пролубникова // Фундаментальные исследования. - 2013. - № 10. - С. 646-649.

11. Дроздов О. И. Управление ликвидностью в процессе исполнения государственного бюджета / О. И. Дроздов // Финансы. - 2009. - № 9. - С. 23-26.

12. Назаров В. В. О совершенствовании механизма управления ликвидностью ЕКС / В. В. Назаров // Финансы. - 2011. - № 7. - С. 25-26.

\section{References}

1. Galukhin A. V. Balanced budget as a condition of its sustainability. Voprosy territorial'nogo razvitiya = Issues of Territorial Development, 2015, no. 1 (21), pp. 1-7. (In Russian).

2. Podyablonskaya L. M. Gosudarstvennoe i munitsipal'noe upravlenie [Governmental and municipal management. Moscow, Yuniti-Dana Publ., 2010. 407 p.

\section{Baikal Research Journal}


3. Kireenko A. P., Chuprov S. V., Sanina L. V. et al. Irkutskaya oblast'v XXI veke: problemy $i$ resursy razvitiya [Irkutsk Oblast in the 21st Century: Problems and Development Resources]. Irkutsk, Baikal State University Economics and Law Publ., 2014. 422 p.

4. Sorokina T. V. Improving regional interbudgetary relations (by the example of Irkutsk Oblast). Izvestiya Irkutskoi gosudarstvennoi ekonomicheskoi akademii = Bulletin of Irkutsk State Economics Academy, 2010, no. 2 (70), pp. 23-30. (In Russian).

5. Kuznetsova E. V. Assessing sustainability quality for the Russian Federation entities' budgets. Finansy = Finance, 2011, no. 2, pp. 20-23. (In Russian).

6. Faiberg T. V. Assessing the dynamics of socially important expenses of Irkutsk Oblast and its determining factors. Izvestiya Irkutskoi gosudarstvennoi ekonomicheskoi akademii = Bulletin of Irkutsk State Economics Academy, 2014, no. 5 (97), pp. 24-27. (In Russian).

7. Rodionova V. M. Sustainability of budgets: theoretical and legal aspects. Finansy = Finance, 2012, no. 2, pp. 54-60. (In Russian).

8. Vlasenko E. O. Investigating methods of providing sustainability for regional budget system. Izvestiya Irkutskoi gosudarstvennoi ekonomicheskoi akademii = Bulletin of Irkutsk State Economics Academy, 2012, no. 5 (85), pp. 37-40. (In Russian).

9. Prokofyev S. E., Sarantsev V. N. Single treasury account of Federal Treasury: state and prospects. Finansy $i$ kredit $=$ Finance and Credit, 2010, no. 11, pp. 4-7. (In Russian).

10. Prolubnikova O. E. Liquidity of single treasury account, development directions and identification of indicators. Fundamental'nye issledovaniya = Fundamental Research, 2013, no. 10, pp. 646-649. (In Russian).

11. Drozdov O. I. Liquidity management in the process of governmental budget performance. Finansy = Finance, 2009, no. 9, pp. 23-26. (In Russian).

12. Nazarov V. V. On improving the mechanism of STA liquidity management. Finansy= Finance, 2011, no. 7, pp. 25-26. (In Russian).

\section{Информация об авторах}

Камашева Татьяна Юрьевна - магистрант, кафедра финансов, Байкальский государственный университет, 664003, г. Иркутск, ул. Ленина, 11, e-mail: kamalisa74@yandex.ru.

Файберг Татьяна Владилировна - кандидат экономических наук, доцент, заведующий кафедрой финансов, Байкальский государственный университет, 664003, г. Иркутск, ул. Ленина, 11, e-mail: faibergtv@mail.ru.

\section{Authors}

Tatyana Yu. Kamasheva - Master Degree Student, Chair of Finance, Baikal State University, 11 Lenin St., 664003, Irkutsk, Russian Federation; e-mail: kamalisa74@yandex.ru.

Tatyana V. Faiberg - PhD in Economics, Associate Professor, Head of Chair of Finance, Baikal State University, 11 Lenin St., 664003, Irkutsk, Russian Federation; e-mail: faibergtv@mail.ru.

\section{Библиографическое описание статьи}

Камашева Т. Ю. Управление ликвидностью единого счета бюджета субъекта Российской Федерации, как метод обеспечения его сбалансированности / Т. Ю. Камашева, T. В. Файберг // Baikal Research Journal. - 2016. - T. 7, № 6. — DOI: 10.17150/2411$\underline{6262.2016 .7(6) .4 .}$.

\section{Reference to article}

Kamasheva T. Yu., Faiberg T. V. Liquidity management for uniform budget account of the Russian Federation entity as a method of providing budget sustainability. Baikal Research Journal, 2016, vol. 7, no. 6. DOI: 10.17150/2411-6262.2016.7(6).4. (In Russian).

\section{Baikal Research Journal}

